\title{
A review on inorganic phosphor materials for white LEDs
}

\author{
Seok Min Hwang, Jae Bin Lee, Se Hyeon Kim and Jeong Ho Ryu ${ }^{\dagger}$ \\ Department of Materials Science and Engineering, Korea National University of Transportation, Chungju 380-702, Korea \\ (Received August 24, 2012)
}

(Revised September 12, 2012)

(Accepted September 28, 2012)

\begin{abstract}
White LEDs (light-emitting diodes) are promising new-generation light sources which can replace conventional lamps due to their high reliability, low energy consumption and eco-friendly effects. This paper briefly reviews recent progress of oxy/nitride host phosphor and quantum dot materials with broad excitation band characteristics for phosphorconverted white LEDs. Among oxy/nitride host materials, $\mathrm{M}_{2} \mathrm{Si}_{5} \mathrm{~N}_{8}: \mathrm{Eu}^{2+}, \mathrm{MAlSiN}_{3}: \mathrm{Eu}^{2+} \mathrm{M}-\mathrm{SiON}(\mathrm{M}=\mathrm{Ca}, \mathrm{Sr}, \mathrm{Ba}), \alpha / \beta-$ SiAlON $: \mathrm{Eu}^{2+}$ are excellent phosphors for white LED using blue-emitting chip. They have very broad excitation bands in the range of $440 \sim 460 \mathrm{~nm}$ and exhibit emission from green to red. In this paper, In this review we focus on recent developments in the crystal structure, luminescence and applications of the oxy/nitride phosphors for white LEDs. In addition, the application prospects and current trends of research and development of quantum dot phosphors are also discussed.
\end{abstract}

Key words Phosphor, White-LEDs, Oxy/nitride, Quantum dots

\section{백색 발광다이오드(White LEDs)용 무기형광체 재료의 연구개발 현황}

황석민, 이재빈, 김세현, 류정호 ${ }^{\dagger}$

한국교통대학교, 신소재공학과, 충주, 380-702

(2012년 8월 24일 접수)

(2012년 9월 12일 심사완료)

(2012년 9월 28일 게재확정)

요 약 백색 발광다이오드(white light-emitting diodes)를 이용한 광소자는 소비전력이 상대적으로 작고, 안정적이며, 수 은과 같은 유해 중금속을 포함하지 않기 때문에, 에너지 절약 및 친환경 산업측면에서 유망한 산업으로 급속히 발전하고 있다. 국내의 경우 LED 조명의 효율, 신뢰성, 연색성을 향상시키는데 필수 소재인 형광체의 기술 확보에 대한 관심이 높아 지고 있다. 이러한 관점에서 기존의 $\mathrm{YAG}, \mathrm{TAG}$, silicate 계열 산화물 형광체 뿐만 아니라 고온특성이 우수한 산/질화물계 형 광체 개발에 대한 관심이 높아지고 있다. 특히 산/질화물계 형광체 조성에서 $\mathrm{M}_{2} \mathrm{Si}_{5} \mathrm{~N}_{8}: \mathrm{Eu}^{2+}, \mathrm{MAlSiN}_{3}: \mathrm{Eu}^{2+} \mathrm{M}-\mathrm{SiON}(\mathrm{M}=$ $\mathrm{Ca}, \mathrm{Sr}, \mathrm{Ba}), \alpha / \beta-\mathrm{SiAlON}: \mathrm{Eu}^{2+}$ 과 같은 재료는 $440 \sim 460 \mathrm{~nm}$ 영역에서의 넓은 여기파장과 우수한 발광효율로 청색 LED 칩을 이용한 백색 $\mathrm{LED}$ 에 넓게 사용되고 있다. 이 논문에서는 이러한 산/질화물계 형광체 조성의 결정학적, 광학적 특성 및 응용 에 대해서 정리하였다. 또한 최근에 주목받고 있는 양자점(quantum dots) 형광체를 응용한 white LEDs의 개발동향에 대해 서도 알아보도록 한다.

\section{1. 서 론}

$\mathrm{LED}$ 는 백열등과 형광등이 각각 $5 \%$ 와 $40 \%$ 의 전기 에너지를 빛 에너지로 변환시킬 수 있는 데 비해 거의 $90 \%$ 이상의 에너지 변환 효율을 가진다. 또한 기존의 조명이 단순히 켜고 끄는 기능에 머물러 있었다면, LED

\footnotetext{
Corresponding author

Tel: +82-43-841-5384

Fax: +82-43-841-5380

E-mail: jhryu@ut.ac.kr
}

는 빛의 밝기와 색을 자유자재로 미세하게 변환시킬 수 있으며 이러한 특성을 이용하여 이전 조명으로 불가능했 던 화려한 색상과 그림들을 $\mathrm{LED}$ 조명으로 구현해 내고 있다. $\mathrm{LED}$ 의 또 다른 중요한 장점은 환경오염의 가능성 이 적다는 것이다. 기존 조명들은 전구 속에 수은 등의 기체를 광원으로 사용하고 있지만 $\mathrm{LED}$ 는 이런 물질들 이 불필요하고, 빛의 파장을 조절할 수 있어 농업용이나 어업용으로 사용이 가능하다. 실제로 정부에서는 시범사 업으로 갈치나 오징어잡이 어선의 집어등으로 $\mathrm{LED}$ 조 명을 사용함으로써 연료절감 효과와 함께 고열과 소음에 


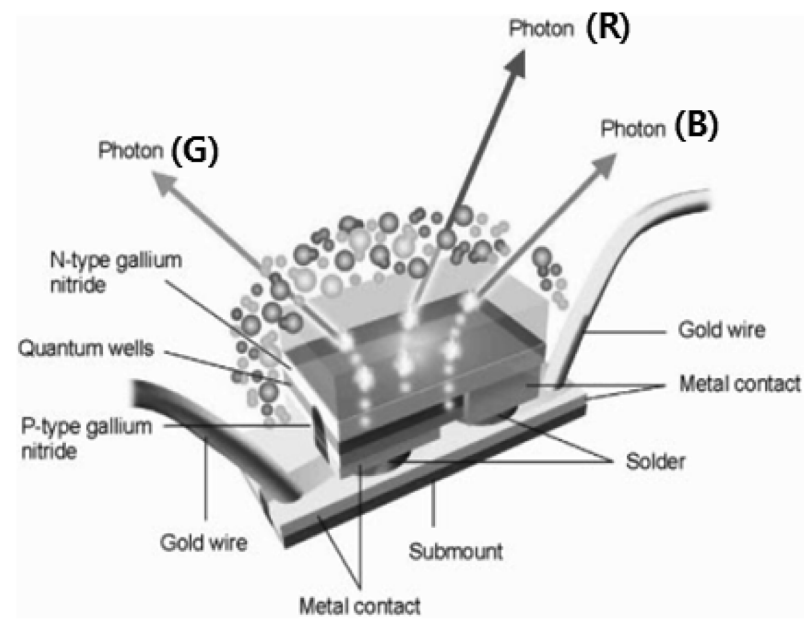

Fig. 1. White LED structure using a blue emitting chip [1].

서 벗어난 쾌적한 어업환경을 제공하고 있으며, 어종 별 로 특정 파장의 빛을 이용해 원하는 어종의 어획량을 높 이는 기술도 사용되고 있다.

이와 같이 $\mathrm{LED}$ 기술 분야에 있어 집중적으로 연구개 발이 진행되고 있는 분야는 조명용 백색 LED 분야 및 디스플레이 소자 분야이다. $\mathrm{LED}$ 는 기본적으로 좁은 파 장영역의 빛만을 발생하므로 단일소자 차원에서 백색광 발현은 기술적으로 난점이 많으며, RGB 삼원색을 조합 하여 백색을 얻는 등의 여러 가지 방안이 시도되었다. 그 중에서도 청색 또는 근자외선 $\mathrm{LED}$ 에 적절한 형광체 분말을 도포하여 chip 발광 파장의 dowon-conversion을 통해 백색광을 발현시키는 방법이 가장 효율적이며 현재 많은 기업에서 실용화 되고 있다(Fig. 1 참조). 따라서 $\mathrm{LED}$ 를 이용한 백색 조명 및 디스플레이 기기의 개발을 위해서는 그 응용분야에 맞는 효율이 우수한 형광체의 개발이 필수적이라 하겠다. 현재까지 $\mathrm{LED}$ 용 형광체를 상용화한 대표적 기업으로는 일본의 Nichia, Toyota Gosei, Mitsubishi Chemical, 독일의 LWB, Osram, 미 국의 Intermatix 등이 있다. 국내의 경우 LED 조명의 효율, 신뢰성, 연색성을 만족할 만한 수준의 특성을 구현 하기 위해 필요한 형광체 합성기술과 특허 확보적인 면 에서 미국, 일본 등 선발 주자에 비해 뒤처져 있는 것이 현실이므로, 관련기술 개발 및 상용화를 위한 투자가 시 급한 상황이다.

고품위 형광체 기술 확보는 LED 제품의 효율, 수명, 연색성 및 색 재현성과 같은 특성을 결정하는 아주 중요 한 요소이기 때문에 국내의 LED산업의 적극적인 육성 을 위해서는 핵심 소재인 형광체 기술의 확보는 반드시 필요하다고 할 수 있다. 최근의 $\mathrm{LED}$ 용 형광체 개발은 기본적인 효율 향상뿐만 아니라 제품 사용 중 광특성 변 화를 최소화 및 장수명을 보장 할 수 있는 신뢰성 향상 기술과, $\mathrm{LCD} \mathrm{BLU}(\mathrm{Backlight} U$ Unit)나 조명, 전장 등 각
각의 응용 분야별로 요구되는 연색성, 색재현성, 색온도 안정성 등을 만족시키기 위한 특화된 형광체 연구가 진 행되어야 한다. 현재 형광체를 모체(host material)의 주 성분 관점으로 논의할 때, 기존의 $\mathrm{YAG}, \mathrm{TAG}$ 및 silicate 계열의 산화물 형광체와 황화물(sulfide) 계열의 종류가 많으나 이들 조성의 형광체는 백색 $\mathrm{LED}$ 에서 요구되는 내구성, 내습성, 색온도 안정성 등의 고신뢰성을 만족시 키기에는 부족하다. 그러나 최근에 연구 개발 및 적용 진행중인 질화물(nitride) 또는 산질화물(oxy-nitride) 모 체는 기존 산화물의 산소대신 질소 원자의 강한 공유결 합으로 이루어져 안정성이 높고, 여기 및 발광파장이 장 파장으로 이동하여 blue광을 이용한 $\mathrm{LED}$ 적용에 적합 하다.

이러한 이유들 때문에 최근 고온 특성이 우수한 질화 물계 형광체 개발에 대한 관심이 높아지고 있으며 신규 형광체로서 상용화 연구가 급속도로 진행 되고 있다. 또 한 나노입자는 고체의 벌크 상태와 비교하여 매우 상이 한 물리/화학/광학/전기 및 표면 특성을 나타내며 이와 같은 흥미로운 물성변화를 기초로 하여 정보통신, 에너 지, 의료 바이오, 우주항공 등의 다양한 분야에서 무한한 응용가능성을 가지고 있다. 특히 발광성 나노입자(양자 점, quantum dot)는 태양전지 및 레이저 같은 분야뿐만 아니라 $\mathrm{LED}$ 에 적용하여 벌크 형광체에 비해 보다 다양 한 광특성을 구현하기 위한 연구가 활발히 진행 중에 있 다. 또한 이와 같은 발광성 나노입자는 일반적으로 사용 되고 있는 유기물 계열의 형광염료(fluorescent dye)와 비교하여 입자의 크기조절에 의한 양자제한효과(quantum confinement effect)를 통해 동일 조성의 다양한 광 스펙 트럼을 구현할 수 있고, $80 \%$ 이상의 매우 높은 양자효 율(quantum yield)과 색순도(color purity)가 매우 우수 한 장점이 있다. 이러한 최근 경향에 맞추어 본고에서는 $\mathrm{LED}$ 용 무기형광체 중 최근의 질화물계 형광체 및 발광 나노입자를 이용한 연구 동향에 대하여 간단히 정리해 보고자 한다.

\section{2. 본 론}

\subsection{LED용 형광체의 개념 및 특성}

형광체란 일반적으로 외부로부터 광에너지를 흡수하여 고유의 광 에너지를 발산하는 물질의 통칭이다. 여기서 의 발광은 금속 원소의 높은 에너지 준위에 있는 전자가 보다 안정한 에너지 준위로 전이하면서 그 차이만큼의 에너지를 빛으로 발산하는 현상(photonic radiation)을 의미한다. 일반적으로 형광체는 Fig. 2 와 같이 모체(host material)와 그 안에 혼입된 활성제 원소(activator)로 크 


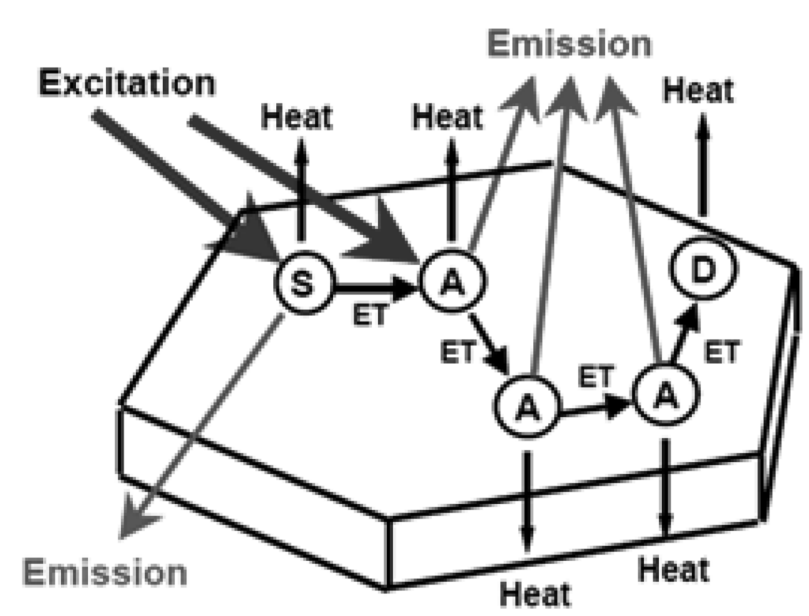

Fig. 2. Schematic diagram for emission mechanism in inorganic phosphor.

게 이루어지며, 이런 활성제들이 모체와 물리적으로 상 호 작용하여 발광과 관련된 에너지 준위의 변화를 발생 하게 된다. 이러한 활성제 원소들과 모체간의 상호작용 은 크게 두 부류로 나눌 수 있으며, 첫째로 그 상호작용 이 상대적으로 약한 경우로 대부분 주기율표 상의 란탄 족 원소들의 이온들이 이에 해당한다. 이러한 란탄족 이 온들은 $4 \mathrm{f}$ 와 $5 \mathrm{~d}$ 궤도함수 사이에서 발생되는 전자 전이 에 의해서 발광특성이 결정된다. 이와는 달리 활성제와 모체간의 상호 작용이 강한 경우로서 주로 활성제 원소 가 3 주기 및 4 주기의 전이금속들이며, 전이금속들의 dd, f-f, d-s 준위간의 전이에 의해 발광 현상이 발생한다.

지금까지 개발된 형광체의 활성제 원소들을 살펴보면 주로 전이금속과 란탄족 금속이온이 활성제 원소로 사용 되고 있음을 알 수 있다. 이러한 활성제 중에 LED 용으 로 주로 활용되고 있는 원소는 $\mathrm{Ce}^{3+}$ 와 $\mathrm{Eu}^{2+}$ 이다. $\mathrm{Ce}^{3+}$ 이온은 산화물에서는 blue-green, 황화물에서는 orangered 그리고 잘 알려진 YAG 구조에서는 yellow-orange 광을 발산하는 것으로 알려져 있다. 또한 $\mathrm{Eu}^{2+}$ 이온은 대부분의 모체에서 blue부터 red까지 다양한 발광 특성 을 보여준다. 특히 질화물계 모체에서는 산화물에 비해 아주 우수한 특성의 green-red 발광 특성을 보여준다. 이러한 활성제의 모체에 따른 발광색의 변화는 활성제 이온의 에너지 상태가 모체의 결정장(crystal field) 에너 지의 차이에 따라 다르게 나타나기 때문이다. 이는 $4 \mathrm{f}$ 궤도의 전자가 $5 \mathrm{~d}$ 궤도로 전이될 경우에 $4 \mathrm{f}$ 궤도에 전 자가 있을 경우는 외부의 $\mathrm{s}$ 와 $\mathrm{p}$ 궤도에 의하여 차폐되어 결정장의 영향을 거의 받지 않지만, $\mathrm{d}$ 궤도로 여기되었 을 경우 외부 결정장의 영향을 크게 받게 되는 것으로 설명된다. 또한 활성제가 흡수된 에너지를 효율적으로 전달하기 위해 사용되는 원소를 증감제(sensitizer)라고 하며, 이때 모체는 단순히 활성제를 격자내에 고정시켜 주는 역할을 하고, 증감제는 흡수된 에너지를 활성제로
효과적으로 전달하는 역할을 하게 된다. 하지만 모체는 활성제 주위의 결정장 대칭과 배열 등에 큰 영향을 미쳐 발광 스펙트럼의 모양과 중심 파장 위치 및 열적 안정성 등을 결정하는데 중요한 역할을 하게 된다. 즉 동일한 활성제 원소가 각각 다른 모체에 혼입되어 있을 때 각기 다른 발광특성을 나타내는 것은 이러한 이유에서이다.

\section{2. $\mathrm{LED}$ 용 질화물계 $\mathrm{RGY}$ 형광체 개발 동향}

적색 형광체는 일반적으로 백색 $\mathrm{LED}$ 를 구현할 청색 LED chip을 주광원으로 녹색(green), 황색(yellow) 혹은 청색(blue) 형광체와 같이 blending 하여 사용한다. 백색 $\mathrm{LED}$ 에서의 적색 형광체 적용 연구는 주로 $\mathrm{Eu}^{3+}$ 를 활성 제로 사용하는 산화물계 조성(e.g. $\left.\mathrm{NaEu}(\mathrm{W}, \mathrm{Mo})_{2} \mathrm{O}_{8}\right)$ 과 $\mathrm{Eu}^{2+}$ 를 활성제로 사용하는 황화물 조성계(e.g. $\mathrm{Ca}(\mathrm{Sr}) \mathrm{S}$ : $\left.\mathrm{Eu}^{2+}\right)$ 로 이루어져 왔다. 하지만 이러한 형광체 조성들은 청색 영역에서의 낮은 여기 특성(산화물)과 매우 열악한 화학적 안정성(황화물)을 가지고 있어 그 응용에 많은 제한이 있었다. 따라서 화학적 안정성이 뛰어나고 청색 영역에서 높은 여기 특성을 가지는 새로운 형광체 조성 에 대한 연구가 절실한 실정이다. 최근 이러한 문제점들 을 해결할 수 있는 실리콘을 주요 조성으로 하는 질화물 형광체가 개발되어 $\mathrm{LED}$ 에 적용되고 있다. 현재까지 개 발중인 대표적인 질화물계 형광체를 발광 파장별로 분류 하면 Table 1[1-15]과 같다.

$\mathrm{M}_{2} \mathrm{Si}_{5} \mathrm{~N}_{8}: \mathrm{Eu}^{2+}(\mathrm{M}=\mathrm{Ca}, \mathrm{Sr}, \mathrm{Ba}, 258$ phase $)$ 조성은 Schnick [1-4] 등에 의해 최초로 그 결정구조 및 특성에 대한 보 고가 이루어 졌으며, 각각의 결정 시스템은 $\mathrm{Ca}_{2} \mathrm{Si}_{5} \mathrm{~N}_{8}$ 이 monoclinic, $\mathrm{Sr}_{2} \mathrm{Si}_{5} \mathrm{~N}_{8}$ 및 $\mathrm{Ba}_{2} \mathrm{Si}_{5} \mathrm{~N}_{8}$ 은 orthorhombic 구조 를 가지며 대표적인 $\mathrm{Sr}_{2} \mathrm{Si}_{5} \mathrm{~N}_{8}$ 의 결정구조를 나타내면 Fig. 3과 같다. 이러한 258 phase 결정구조에서의 알카 리 토금속 금속들과 질소 원자간의 결합 길이는 평균적 으로 대략 $2.880 \AA$ 로 알려져 있다. 이 조성에서는 알칼 리 토금속의 종류 및 조성비에 따라 orange부터 적색에 이르는 넓은 색특성을 구현할 수 있다고 보고되고 있으

Table 1

Compositions and emission wavelength of representative phosphors [1-15]

\begin{tabular}{|c|c|c|c|}
\hline \multirow[t]{3}{*}{ Blue } & $\mathrm{LaSi}_{3} \mathrm{~N}_{5}: \mathrm{Ce}$ & K. Uheda & $400 \sim 470 \mathrm{~nm}$ \\
\hline & $\mathrm{LaSi}_{5} \mathrm{Al}_{2} \mathrm{ON}_{9}: \mathrm{Ce}$ & N. Hirosaki & $465 \sim 495 \mathrm{~nm}$ \\
\hline & $\mathrm{SrSiAl}_{2} \mathrm{O}_{3} \mathrm{~N}_{2}: \mathrm{Eu}$ & H.T. Hintzen & $460 \sim 480 \mathrm{~nm}$ \\
\hline \multirow[t]{3}{*}{ Green } & $\beta-$ SiAlON : Eu & N. Hirosaki & $530 \sim 540 \mathrm{~nm}$ \\
\hline & $\mathrm{Ln}_{2} \mathrm{Si}_{3} \mathrm{O}_{3} \mathrm{~N}_{4}: \mathrm{Tb}$ & H.T. Hintzen & $540 \sim 545 \mathrm{~nm}$ \\
\hline & $\mathrm{AESi}_{2} \mathrm{O}_{2} \mathrm{~N}_{2}: \mathrm{Eu}$ & W.S. Schnick & $505 \sim 565 \mathrm{~nm}$ \\
\hline \multirow[t]{2}{*}{ Yellow } & $\mathrm{YAG}: \mathrm{Ce}$ & S. Nakarnura & $550 \sim 580 \mathrm{~nm}$ \\
\hline & $\mathrm{La}_{3} \mathrm{Si}_{6} \mathrm{~N}_{11}: \mathrm{Ce}$ & Mitsubishi & \\
\hline \multirow[t]{2}{*}{ Red } & $\mathrm{AE}_{2} \mathrm{Si}_{5} \mathrm{~N}_{8}: \mathrm{Eu}$ & H.A. Hoppe & $580 \sim 625 \mathrm{~nm}$ \\
\hline & $\mathrm{Ca}(\mathrm{Sr}) \mathrm{AlSiN}_{3}: \mathrm{Eu}$ & K. Uheda & $620 \sim 650 \mathrm{~nm}$ \\
\hline
\end{tabular}



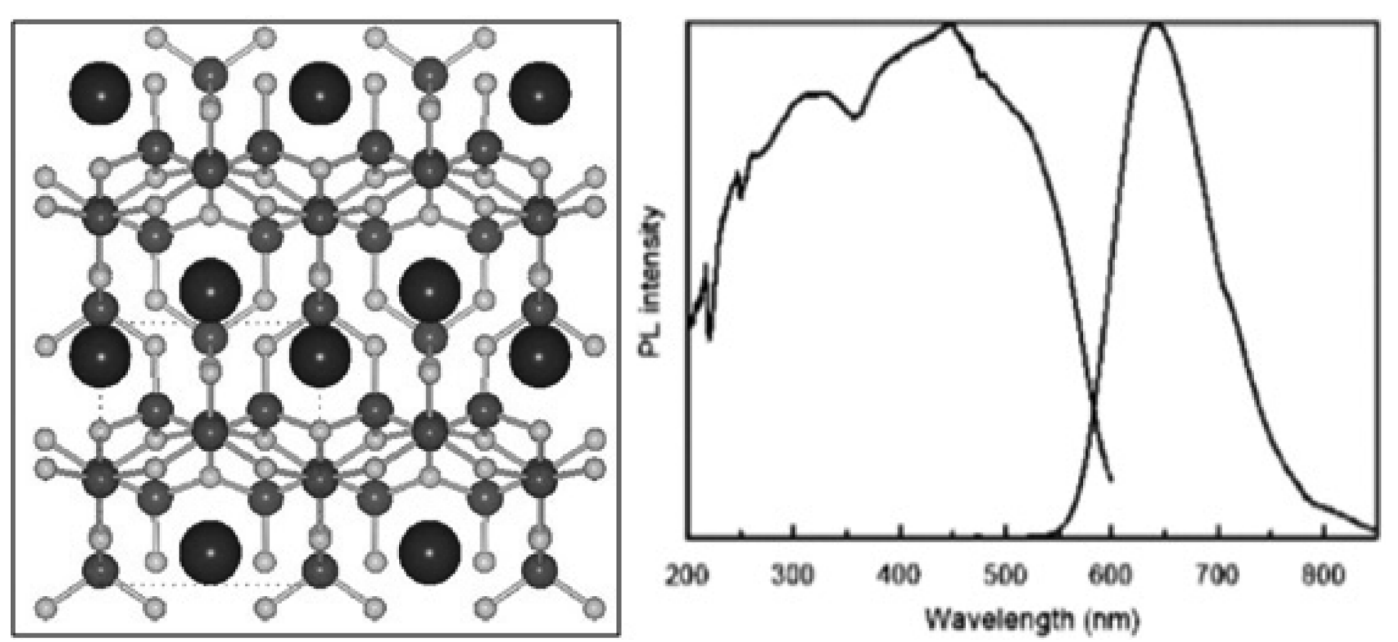

Fig. 3. Crystal structure and emission property of $\mathrm{Sr}_{2} \mathrm{Si}_{5} \mathrm{~N}_{8}: \mathrm{Eu}^{2+}$ red phosphor [1-4].

며, 알카리 토금속의 원자반경이 커짐에 따라, 발광파장 이 적색으로 전이하는데, 이러한 현상은 일반적인 결정 장 이론으로 설명이 가능하다. 이러한 조성을 가지는 형 광체들의 여기 및 발광 스펙트럼은 Fig. 3 과 같이, 400 에서 $450 \mathrm{~nm}$ 근방에서의 넓은 여기 특성을 나타내고 있 으며 이러한 근자외 및 청색 영역에서의 높은 여기특성 은 이 형광체 조성의 $\mathrm{LED}$ 적용가능성을 높여주는 중요 한 특성이다. 또한 Fig. 4에 대표적인 $\mathrm{Sr}_{2} \mathrm{Si}_{5} \mathrm{~N}_{8}: \mathrm{Eu}^{2+}$ 조 성의 열적 소광현상(thermal quenching) 특성을 나타내 고 있으며, 이후에 설명할 또 다른 주요 Red 형광체인 $\mathrm{CaAlSiN}_{3}: \mathrm{Eu}^{2+}$ 형광체 조성과 유사한 특성을 보여주고 있다. 여기서 $150^{\circ} \mathrm{C}$ 에서의 $\mathrm{PL}$ 강도는 상온대비 약 $85 \%$ 로 아주 우수한 열적 안정성을 나타낸다.

상기에 설명한 258 조성 형광체와 함께 현재 개발된 red 형광체 중 가장 대표적인 Red 조성인 $\mathrm{MAlSiN}_{3}$ : $\mathrm{Eu}^{2+}(\mathrm{M}=\mathrm{Ca}, \mathrm{Sr})[5-7]$ 는 orthorhombic 결정구조를 가지며 Fig. 4에서와 같이 $(\mathrm{Si} / \mathrm{Al}) \mathrm{N}_{4}$ 사면체가 3차원적으로 연결 되어 있는 구조로 이루어져 있다. 이 구조에서 $\mathrm{Al}$ 및 $\mathrm{Si}$ 원자들은 동일한 사면체 자리에 불규칙적으로 분포되어

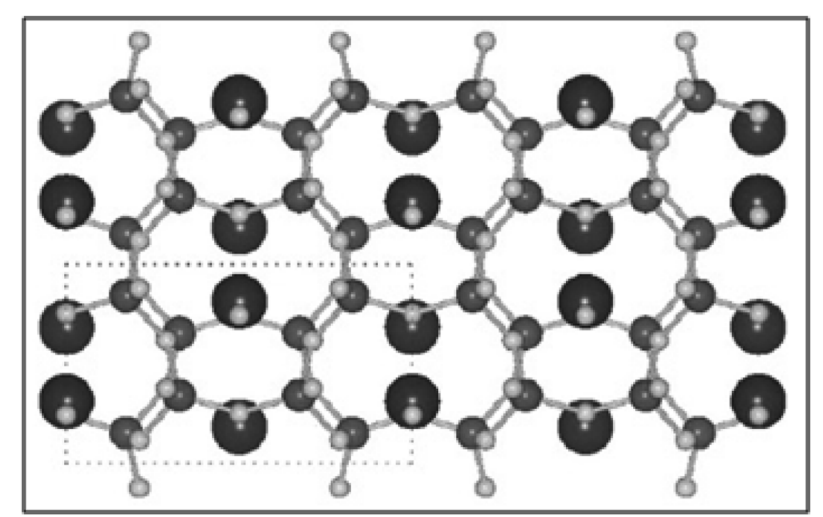

있고 질소 원자와 결합하여 존재하며, 금속 원자와 질소 원자들 간의 평균 거리는 약 $2.451 \AA$ 로 알려져 있다. 이 조성의 형광체는 $600 \mathrm{~nm}$ 이상의 적색을 구현할 수 있는 것으로 알려져 있고, $\mathrm{M}$ 자리의 알카리 토금속의 조성 및 함량비를 조절하여 폭넓은(orange-red) 색역을 조절할 수 있다. 이조성의 광특성은 Fig. 3 에서의 $\mathrm{M}_{2} \mathrm{Si}_{5} \mathrm{~N}_{8}: \mathrm{Eu}^{2+}$ 조성의 형광체와 유사한 특성을 나타내며, 400 부터 450 $\mathrm{nm}$ 에서의 강하고 넓은 여기 특성으로 현재 white-LED 에 널리 적용되고 있다. 열적 소광특성 또한 Fig. 4에서 $150^{\circ} \mathrm{C}$ 에서 상온대비 약 $89 \%$ 의 $\mathrm{PL}$ 특성으로 높은 열적 안정성을 보여주고 있다.

질화물계 Green 형광체의 주요 조성을 크게 두 가지 로 분류하면 $\mathrm{M}-\mathrm{SiON}$ 계열과 $\mathrm{SiAlON}$ 계열로 분류할 수 있다[8-10]. 발광중심으로 작용하는 첨가물로는 $\mathrm{Eu}$, $\mathrm{Ce}, \mathrm{Mn}, \mathrm{Dy}$ 등이 주로 사용되며 현재 상용화에 근접한 형광체는 $\mathrm{Eu}^{2+}$ 을 첨가한 형광체가 대부분이다. $\mathrm{Eu}^{2+}$ 가 첨가된 $\mathrm{M}-\mathrm{SiON}$ 은 청색부터 녹색영역까지의 발광특성을 보여주며 여기에 금속 $(\mathrm{M})$ 이 첨가되는 양 및 $\mathrm{O} / \mathrm{N}$ 비율 에 따라 주 발광파장이 변화하게 된다. 이중 $\beta-\mathrm{SiAlON}$

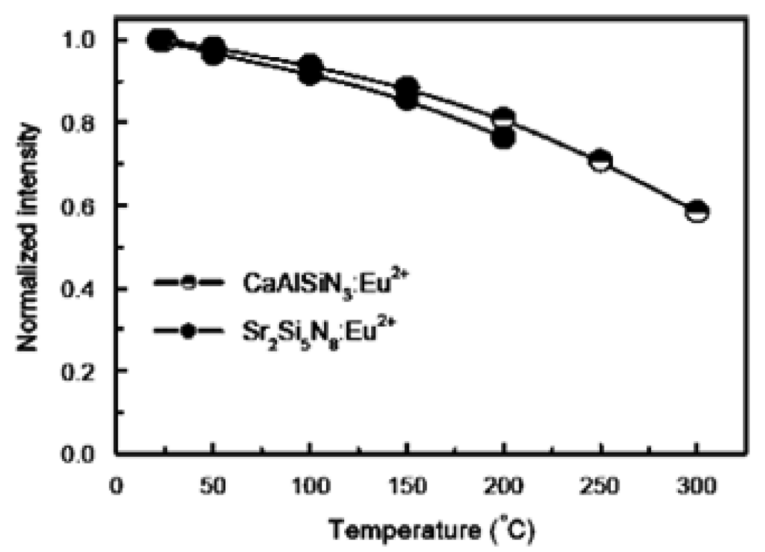

Fig. 4. Crystal structure and thermal quenching property of $\mathrm{CaAlSiN}_{3}: \mathrm{Eu}^{2+}$ red phosphor [5-7]. 

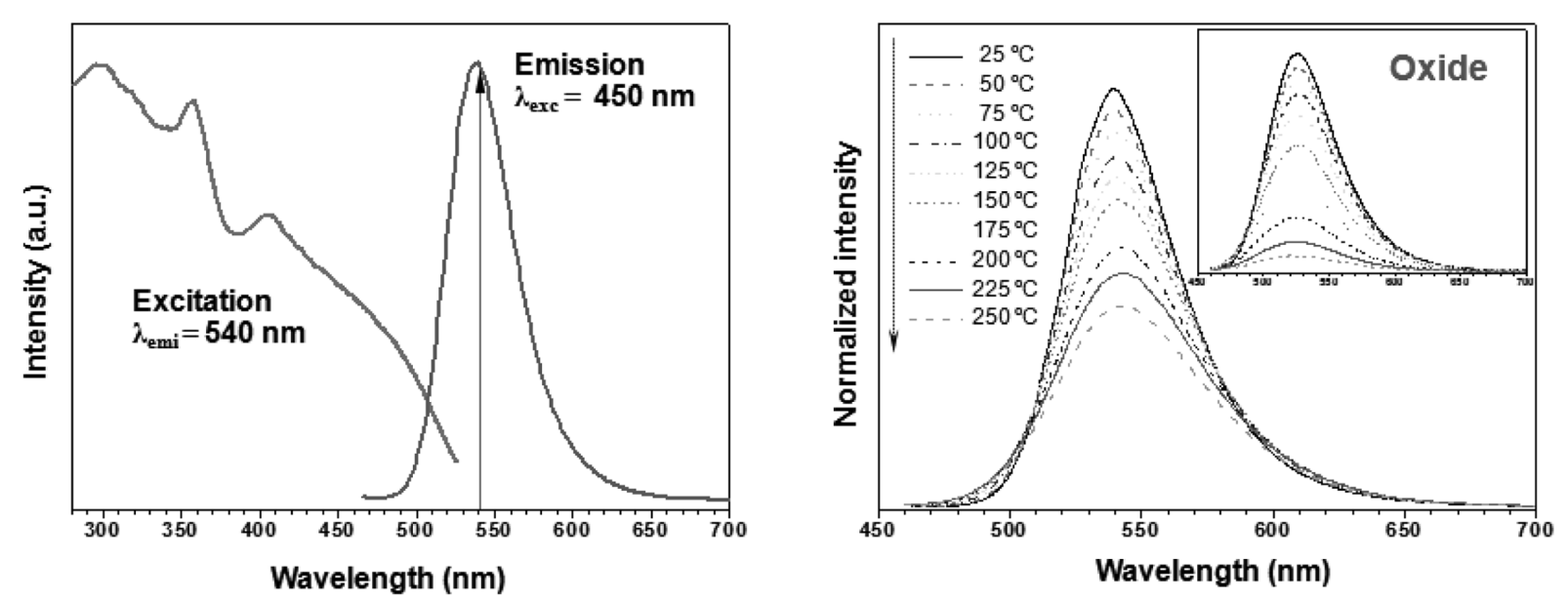

Fig. 5. Emission and thermal quenching property of $\beta-\mathrm{SiAlON}: \mathrm{Eu}^{2+}$ green phosphor $[8,11]$.
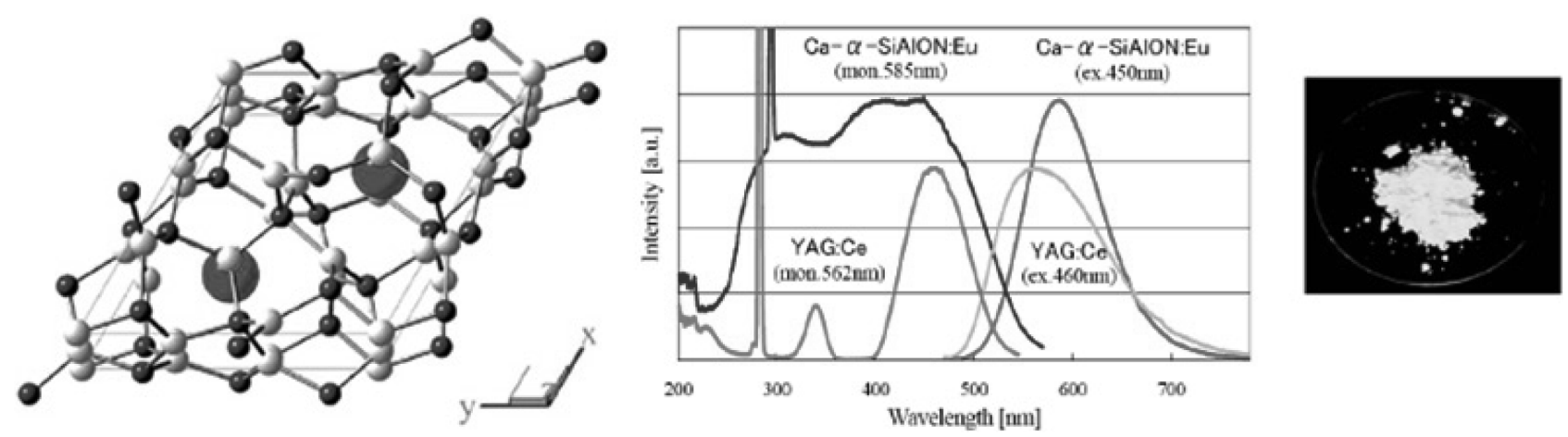

Fig. 6. Crystal structure and emission propertiesof $\mathrm{Ca}-\alpha-\mathrm{SiAlON}: \mathrm{Eu}^{2+}$ yellow phosphor [12-14].

은 $\left[\mathrm{Si}_{6} \mathrm{~N}_{8}\right]$ 의 기본 질화규소 조성에 $\mathrm{Al}$ 을 첨가하는 양에 따라 $\mathrm{O} / \mathrm{N}$ 비율 및 $\mathrm{Si}$ 의 농도가 변하는 결정학적 구조 를 가지며, $\mathrm{Eu}^{2+}$ 가 첨가된 $\beta-\mathrm{SiAlON}$ 형광체 조성은 현 재 상용화에 가장 근접한 형광체로 Fig. 5에서 보여지는 바와 같이 근자외부터 청색의 넓은 영역에서 높은 여기 효율을 보이며, 열에 의한 열화가 작은 장점을 가지고 있다. 발광파장은 $\mathrm{Al}$ 농도 및 $\mathrm{O} / \mathrm{N}$ 비율에 따라 530 $545 \mathrm{~nm}$ 까지 조절이 가능하다. 발광영역의 반치폭은 조 성에 따라 40 55 nm로 silicate 및 다른 산질화물계 형 광체와 비교하여 좁은 특징을 보이며, 이는 BLU 등의 응용에서 색순도를 높일 수 있는 장점으로 작용할 수 있다.

마지막으로 yellow 형광체는 CCFL, 백열전등과 형광 등을 대체하는데 있어서 광도, 연색지수와 색온도 등 고 품위 성능지수의 특성을 좌우하는 핵심적인 광변환 소재 로써 적색 및 녹색 형광체와 혼용하여 $\mathrm{LED}$ 에 사용된다. 이러한 yellow 형광체들 중 가장 잘 알려진 YAG 등의 산화물 계열 조성은 일본 Nichia 및 몇몇 선진업체들이 특허권 및 상용화 기술을 거의 독점하고 있기 때문에 종 래의 산화물 형광체를 대신하는 새로운 조성의 고효율 형광 재료 연구가 시급하다. 이와 같은 배경으로 인하여
강한 공유결합성과 낮은 전자친화도에 기인하여 온도 안 정성, 내구성 및 장파장 발광 특성이 우수한 (산)질화물 계 yellow 형광체에 대한 연구가 집중적으로 이루어지고 있다. 이것은 형광체 기술 확보 여부가 향후 LED 조명 시장의 제품 경쟁력 확보에 직결되어 있을 뿐만 아니라, 장기적으로는 조명의 내구성 향상을 위해 종래의 산화물 형광체를 질화물/산질화물 형광체로 대체하고자 하기 때 문이다.

특히 산질화물인 $\alpha-\mathrm{SiAlON}: \mathrm{Eu}^{2+}$ 조성을 모체로 하는 형광체는 조성 범위가 넓고, 조성 제어에 의해 yellow에 서 orange 영역까지의 소재로 일본의 NIMS를 중심으로 연구개발 및 상용화가 진행되고 있다[12-14]. $\alpha-\mathrm{SiAlON}$ 의 결정구조는 $\mathrm{Si}^{4+}$ 를 $\mathrm{Al}^{3+}$ 가 대체하고 $[\mathrm{Si}, \mathrm{Al}]-[\mathrm{O}, \mathrm{N}]$ 구조 에 있는 격자간 위치 자리에 $\mathrm{Li}, \mathrm{Ca}, \mathrm{Y}$ 와 같은 양이온 이 들어가서 안정화를 시켜줌으로써 $\left[\alpha-\mathrm{Si}_{12} \mathrm{~N}_{16}\right]$ 의 기본 구조로부터 얻어지며 M- $\alpha-\mathrm{SiAlON}$ 구조를 Fig. 6에 나 타내었다. 여기서 가장 효율이 높은 것으로 알려진 $\mathrm{Ca}-$ $\alpha$-SiAlON 황색 형광체의 여기 스펙트럼의 경우 Fig. 6 과 같이 $\lambda_{\mathrm{em}}=570 \mathrm{~nm}$ 영역대를 기준으로 $300 ~ 450 \mathrm{~nm}$, 발광스펙트럼의 경우, $\lambda_{\mathrm{ex}}=450 \mathrm{~nm}$ 영역대를 기준으로 $500 \sim 600 \mathrm{~nm}$ 영역까지 보고 되었다[15]. 


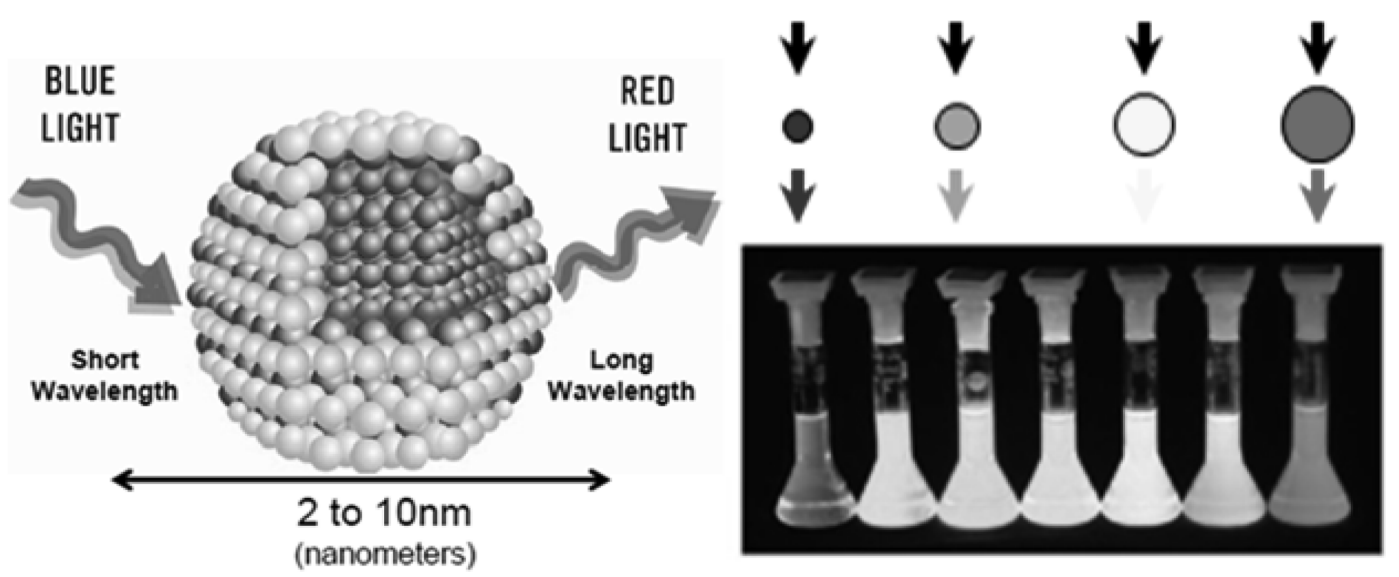

Fig. 7. Variation of emission wavelength with particle size of QD phosphor [16,17].
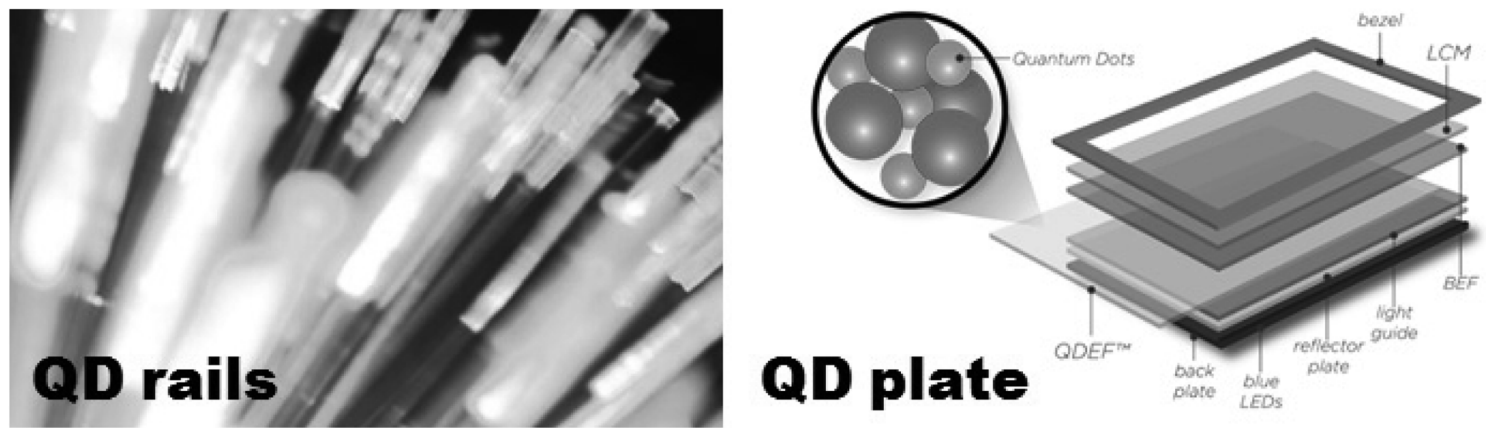

Fig. 8. Photograph of QD rail and schematic diagram of QD plate [18].

\subsection{LED용 양자점 형광체 개발 동향}

현재 가장 잘 알려져 있는 $\mathrm{CdSe}$ 와 같은 $\mathrm{II}-\mathrm{VI}$ 족 화합 물 반도체 양자점(quantum dot, QD)은 높은 발광효율 및 안정성으로 $\mathrm{LED}$ 등에 대한 폭넓은 적용이 검토되어 왔다. Fig. 7[16, 17]은 양자점의 재료와 크기에 따른 방 출 파장을 비교 하여 나타내었는데 일반적으로 반도체 밴드 갭이 좁을수록 장파장의 빛을 방출한다. 그림에서 와 같이 백색광을 구현하는 데 사용할 수 있는 양자점으 로는 $\mathrm{ZnSe}, \mathrm{CdSe}, \mathrm{InGaP}$ 등을 예로 들 수 있지만 주로 가시광선 영역을 다 포함하는 $\mathrm{CdSe}$ 양자점이 연구되어 왔다. $\mathrm{CdSe}$ 녹색의 경우는 청색과 자색 $\mathrm{LED}$ 에서 70 $80 \%$ 효율을 보이며, $\mathrm{CdSe}$ 자주색의 경우는 자색 $\mathrm{LED}$ 에서 $70 \%$ 의 효율을 보이고, $\mathrm{InGaP}$ 자주색의 경우에는 자색 $\mathrm{LED}$ 에서 $50 \%$ 의 효율을 보이고 있다. 하지만 $\mathrm{Cd}$ 과 같은 인체 및 환경에 유해한 원소들이 이 조성의 주 요한 성분이므로 향후 적용 범위 측면에서 큰 제약이 따 른다. 따라서 최근에는 이러한 II-VI 족 양자점 형광체 를 대체할 수 있는 Cd-free 조성 즉, III-V족 혹은 I-IIIVI족 등의 삼성분계 화합물이 많이 연구되고 있다. 특히 이중 $\mathrm{InP}$ 조성은 II-VI족 화합물 반도체와 비교하여 무 독성의 장점과 $\mathrm{CdSe}$ 양자점과 유사한 발광영역 및 양호
한 발광효율로 활용 가능성이 가장 높은 것으로 평가되 고 있다[16, 17].

이러한 QD 형광체는 수분 및 열에 아주 취약하기 때 문에 일반적인 무기형광체를 $\mathrm{LED}$ 에 적용하는 방식으로 적용하기에는 어려움이 따른다. 최근에는 이런한 화확적 불안정성을 극복하기 위해 Fig. 8[18]과 같이 QD 형광 체를 얇은 관에 삽입한 후 밀봉하는 $\mathrm{QD}$ rail 혹은 폴리 머 계열의 plate에 도포하여 적용하는 방법들이 검토되 고 있다.

반도체 계열의 양자점이 아닌 비양자점 나노형광체에 대한 연구는 주로 란탄족 계열의 이온들이 도핑된 기존 형광체 조성을 나노입자화하는 연구의 형태로 진행되고 있다. 나노 형광체라고 하면 일반적으로 $100 \mathrm{~nm}$ 이하의 크기를 갖는 형광체를 의미하며, 수많은 기존의 형광체 조성을 활용하여 다양한 합성법을 통해 연구되어 왔다. 그러나 LED 적용의 측면에서는 마이크로 사이즈의 기 존 형광체에 비해 그 발광 휘도가 현저히 저하되고 분산 성이 결여되어 있어 제품적용 등의 활용 범위는 극히 제 한되어 있는 것이 사실이다. 대표적으로 연구되고 있는 물질로는 강한 적색 발광 특성을 보여주는 $\mathrm{Y}_{2} \mathrm{O}_{3}: \mathrm{Eu}^{3+}$ 와 $\mathrm{YVO}_{4}: \mathrm{Eu}^{3+}$ 등이 있다. $\mathrm{YVO}_{4}: \mathrm{Eu}^{3+}$ 의 경우 $\left[\mathrm{VO}_{4}\right]^{3-}$ 으로부터 $\mathrm{Eu}^{3+}$ 로의 효율적인 에너지 전이로 인해 벌크 
물질의 경우 양자효율이 $70 \%$ 에 이르며, 이와 같이 높 은 양자효율을 갖는 형광체 물질을 중심으로 나노사이즈 화 하는 연구가 진행되고 있다[19]. 또한 $\mathrm{LaPO}_{4}$ 가 우수 한 발광특성으로 인하여 많은 연구가 진행되고 있으며, 이 조성에서 각기 다른 종류의 란탄족 원소 $(\mathrm{Ce}, \mathrm{Eu}, \mathrm{Tb}$, $\mathrm{Dy})$ 를 활성제로 이용하여 각기 다른 파장의 발광특성을 발현하는 것이 보고되고 있다[20].

\section{3. 결 론}

본 논문에서는 white-LED용 무기형광체의 기술 현황 에 대해 개략적으로 살펴보았다. LED 산업은 현재의 주 광원들을 대체할 수 있는 친환경 녹색산업의 한 예로서, 본문에서 살펴본 바와 같이 탄소 에너지 절감과 효율향 상 면에서 빠른 시간 안에 가장 현실적으로 우리 실생활 을 변화시킬 수 있는 가장 대표적인 정책대안이라 하겠 다. 현재 이러한 LED 분야에 있어 가장 역동적인 연구 개발이 진행되고 있는 분야는 조명용 백색 LED 분야, 디스플레이 소자 분야 및 의료/바이오 산업 분야이다. 이러한 분야의 지속적인 발전을 위해서는 그 응용분야에 적절한 우수한 형광체의 원천 기술 개발과 합성/응용/나 노화/저비용 기술개발의 현실적이면서도 비약적인 발전 이 절실하다. 최근에는 국내 학계 및 정부에서도 이러한 형광체 기술의 중요성에 대한 인식이 높아지고 있으나, 일본 및 미국과 같은 선진국들에 비해서는 아직도 연구 환경이나 기업들의 투자 등에 있어서 많이 부족한 것이 현실이다. 따라서 국내 LED 기술에 대한 산 - 학 - 연 공 동의 지속적인 높은 관심과 정부차원에서의 집중적인 지 원 및 투자가 필요하다고 판단된다.

\section{감사의 글}

본 과제(결과물)는 교육과학기술부의 재원으로 지원을 받아 수행된 산학협력 선도대학(LINC) 육성사업의 연구 결과입니다.

\section{참 고 문 헌}

[ 1 ] R. Mueller-Mach, G. Mueller, M.R. Krames, H.A. Höppe, F. Stadler, W. Schnick, T. Juestel and P. Schmidt, "Highly efficient all-nitride phosphor-converted white light emitting diode", Phys. Stat. Sol. (a) 202 (2005) 1727.

[2] H.A. Höppe, F. Stadler, O. Oeckler and W. Schnick, " $\mathrm{Ca}\left[\mathrm{Si}_{2} \mathrm{O}_{2} \mathrm{~N}_{2}\right]$ - ein neuartiges schichtsilicat", Angew.
Chem. 116 (2004) 5656.

[ 3 ] R.-J. Xie and N. Hirosaki, "Silicon-based oxynitride and nitride phosphors for white LEDs - A review", Sci. Technol. Adv. Mat. 8 (2007) 588.

[4] Y.Q. Li, A.C.A. Delsing, G. de With and H.T. Hintzen, "Luminescence properties of $\mathrm{Eu}^{2+}$-activated alkalineearth silicon-oxynitride $\mathrm{MSi}_{2} \mathrm{O}_{2-\delta} \mathrm{N}_{2+2 / 3 \delta}(\mathrm{M}=\mathrm{Ca}, \mathrm{Sr}$, $\mathrm{Ba}$ ): A promising class of novel LED conversion phosphors", Chem. Mater. 17 (2005) 3242.

[ 5 ] W.M. Yen and H. Yamamoto (EDT), Phosphor Handbook, $2^{\text {nd }} \mathrm{Ed},(\mathrm{CRC}$ Press, 2007), pp. 331.

[6] R.-J. Xie, N. Hirosaki, T. Suehiro, F.-F. Xu and M. Mitomo, "A simple, efficient synthetic route to $\mathrm{Sr}_{2} \mathrm{Si}_{5} \mathrm{~N}_{8}$ : $\mathrm{Eu}^{2+}$-based red phosphors for white light-emitting diodes", Chem. Mater. 18 (2006) 5578.

[7] K. Uheda, N. Hirosaki, Y. Yamamoto, A. Naito, T. Nakajima and H. Yamamoto, "Luminescence properties of a red phosphor, $\mathrm{CaAlSiN}_{3}: \mathrm{Eu}^{2+}$ for white light-emitting diodes", Electrochem. Solid State Lett. 9 (2006) $\mathrm{H} 22$.

[ 8 ] J.H. Ryu, H.S. Won, Y.-G. Park, S.H. Kim, W.Y. Song, H. Suzuki and C. Yoon, "Synthesis of $\mathrm{Eu}_{\mathrm{x}} \mathrm{Si}_{6-z} \mathrm{Al}_{\mathrm{z}} \mathrm{O}_{z} \mathrm{~N}_{8-\mathrm{z}}$ green phosphorand its luminescent properties", Appl. Phys. A, 95 (2009) 747.

[9] W. Schnick, "Nitridosilicates, oxonitridosilicates (sions), and oxonitridoaluminosilicates (sialons): New materials with promising properties", Int. J. Inorg. Mater. 3 (2001) 1267.

[10] X. Song, R. Fu, S. Agathopoulos, H. He, X. Zhao and X. Yu, "Synthesis of $\mathrm{BaSi}_{2} \mathrm{O}_{2} \mathrm{~N}_{2}: \mathrm{Ce}^{3+}, \mathrm{Eu}^{2+}$ phosphors and determination of their luminescence properties", J. Am. Ceram. Soc. 94 (2011) 501.

[11] D.S. Yoo, J.H. Ryu, H.-L. Park, S.-H. Lee and Y.-C. Chung, "Atomic and electronic structure investigation and luminescence property of $\mathrm{Eu}^{2+}$-doped SiAlON green phosphor: Ab initio calculations", Jap. J. Appl. Phys. 49 (2010) 06GJ07.

[12] R.-J. Xie, N. Hirosaki, M. Mitomo, K. Takahashi and K. Sakuma, "Highly efficient white-light-emitting diodes fabricated with short-wavelength yellow oxynitride phosphors", Appl. Phys. Lett. 88 (2006) 101104.

[13] R.-J. Xie, N. Hirosaki, M. Mitomo, K. Takahashi, K. Sakuma and N. Kimura, "Wavelength-tunable and thermally stable $\mathrm{Li}-\alpha$-sialon: $\mathrm{Eu}^{2+}$ oxynitride phosphors for white light-emitting diodes", Appl. Phys. Lett. 89 (2006) 241103.

[14] R.-J. Xie, N. Hirosaki, K. Sakuma, Y. Yamamoto and M. Mitomo, "Eu ${ }^{2+}$-doped $\mathrm{Ca}-\alpha-\mathrm{SiAlON}$ : A yellow phosphor for white light-emitting diodes", Appl. Phys. Lett. 84 (2004) 5404.

[15] J.H. Ryu, Y-G. Park, H.S. Won, S.H. Kim, H. Suzuki, J.M. Lee, C. Yoon, M. Nazarov, D.Y. Noh and B. Tsukerblat, "Luminescent properties of $\mathrm{Ca}-\alpha-\mathrm{SiAlON}: \mathrm{Eu}^{2+}$ phosphors synthesized by gas-pressured sintering", J. Electrochem. Soc. 155 (2008) J99.

[16] O.I. Micic, J. Sprague, Z.H. Lu and A.J. Nozik, "Highly efficient bandedge emission from InP quantum dots", Appl. Phys. Lett. 68 (1996) 3150.

[17] D.V. Talapin, N. Gaponik, H. Borchert, A.L. Rogach, M. Haase and H. Weller, "Etching of colloidal InP nanocrystals with fluorides: photochemical nature of the 
process resulting in high photoluminescence efficiency", J. Phys. Chem. B, 106 (2002) 12659.

[18] http://www.nanosysinc.com, webpage, Nanosys, Inc.

[19] G. Pan, H. Song, X. Bai, Z. Liu, H. Yu, W. Di, S. Li, L. Fan, $\mathrm{X}$. Ren and S. Lu, "Novel energy-transfer route and enhanced luminescent properties in $\mathrm{YVO}_{4}: \mathrm{Eu}^{3+} /$
$\mathrm{YBO}_{3}: \mathrm{Eu}^{3+}$ composite", Chem. Mater. 18 (2006) 4526.

[20] K. Riwotzki, H. Meyssamy, A. Kornowski and M. Haase, "Liquid-phase synthesis of doped nanoparticles: Colloids of luminescing $\mathrm{LaPO}_{4}$ : Eu and $\mathrm{CePO}_{4}$ : Tb particles with a narrow particle size distribution", J. Phys. Chem. B 104 (2000) 2824. 